\title{
Progress on the $2 X$ Upper Stage Engine for the Ares I Crew Launch Vehicle and the Ares V Cargo Launch Vehicle
}

\author{
Thomas D. Byrd, Deputy Manager, and Michael H. Kynard, Manager \\ Upper Stage Engine Element Office \\ Ares Projects Office \\ NASA Marshall Space Flight Center \\ Huntsville, AL 35812
}

\section{Presentation Abstract}

NASA's Vision for Exploration requires a safe, reliable, affordable upper stage engine to power the Ares I Crew Launch Vehicle (CLV) and the Ares V Cargo Launch Vehicle. The J-2X engine is being developed for that purpose, epitomizing NASA's philosophy of employing legacy knowledge, heritage hardware, and commonality to carry the next generation of explorers into low-Earth orbit and out into the solar system. This presentation gives top-level details on accomplishments to date and discusses forward work necessary to bring the J-2X engine to the launch pad. 
MSFC-587-Presentation

\section{Progress on the J-2X Upper} Stage Engine for the Ares I Crew Launch Vehicle glsus the Ares V Cargo Laund CDE Vińlele

Thomas D. Byrd, Deputy Manerger, Michael H. KYynard, Manager, Upper Stage Engine Element NASA Marshall Space Flight Center

AIAA Space 2007 Conference \&: Exposition September 2007 


\section{Agenda}

- Overview of the Ares Launch Vehicles and mission

- J-2X heritage and design evolution

- Current design requirements and status

2006-2007 progress

- Forward work and conclusions 


\section{Overview of the Exploration Launch Projects Architecture}

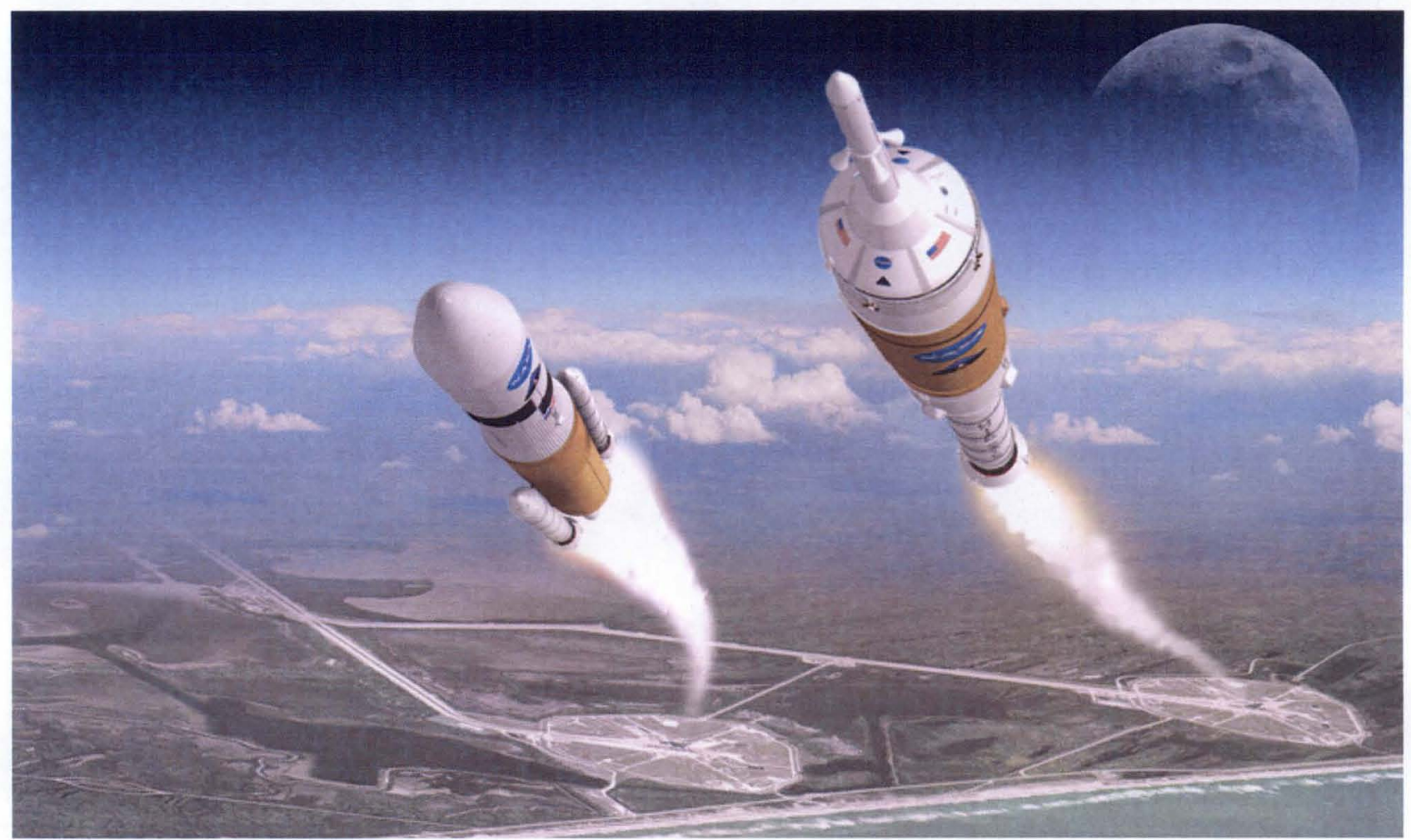

- Safe, reliable, affordable space transportation

- Based on heritage hardware and legacy knowledge

- Separates cargo from crew

- Ares V (left) delivers heavy exploration cargo to Low Earth Orbit

- Ares I (right) delivers crew and cargo to LEO, International Space Station 


\section{The Lunar Mission Scenario}

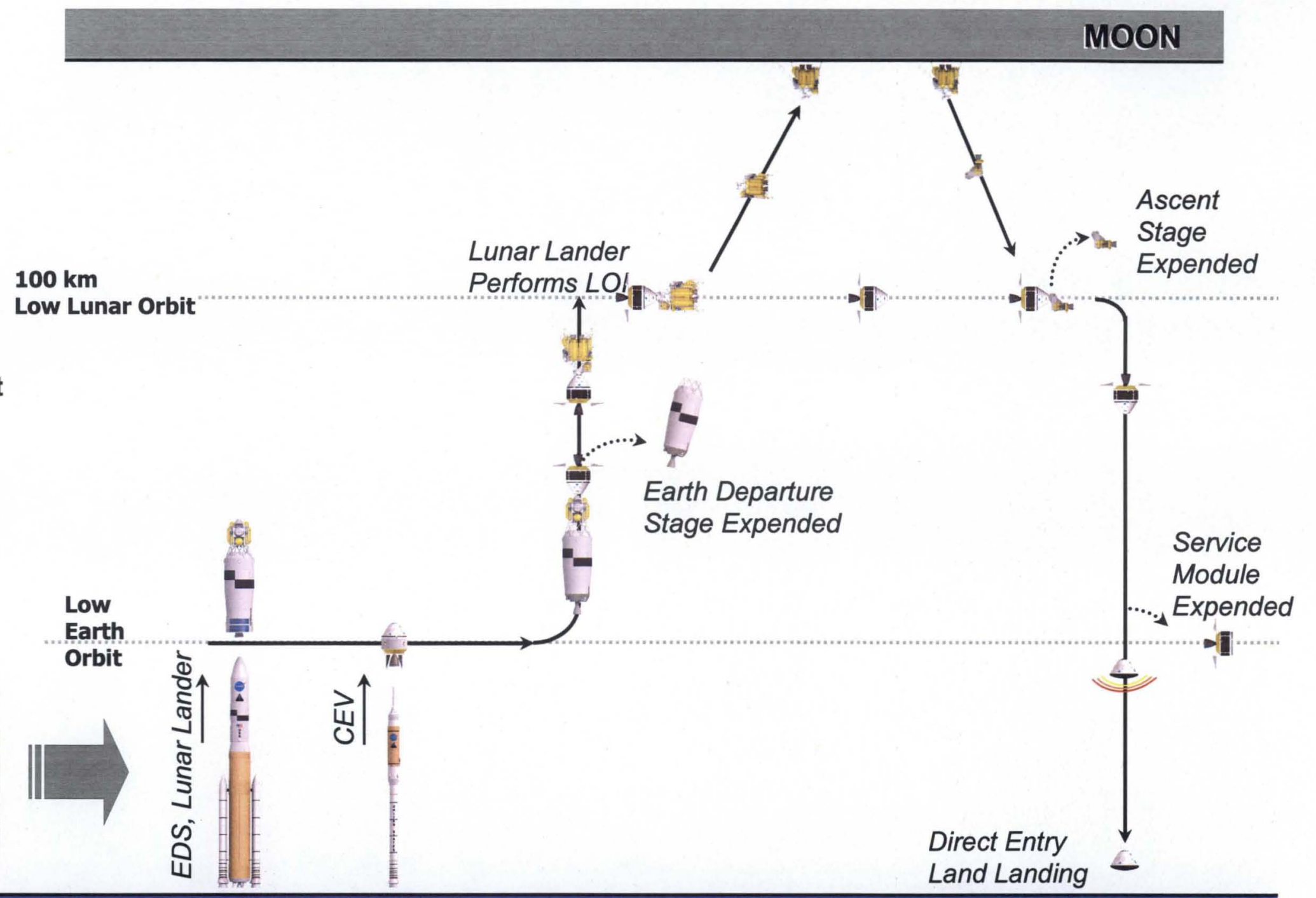

\section{EARTH}




\section{J-2X Development Philosophy}

- One Engine

- From the beginning, the goal has been to undertake a single engine development cycle in order to fulfill the needs of both Ares I and Ares V.

- Requirements Driven

- This is a flight hardware development project, not a technology development effort.

- Engine capabilities and characteristics are pursued because they exist as architecture requirements.

- Leverage Heritage Hardware and Legacy Knowledge

- A significant reduction in overall project risk expected through the utilization of $\mathrm{J}-2$, $\mathrm{J}-2 \mathrm{~S}$, and RS-68 experience and the relatively recent XRS-2200 development.

- Thus, the goal is to leverage heritage designs and experience to the maximum extent practical.

- Aggressive Schedule

- Because the engine is expected to be the critical path for the vehicle, the approach is to pursue an extremely aggressive schedule.

- Early Risk Reduction

- An element of the aggressive schedule is to include risk reduction testing at component and subsystem level (where it makes sense) as early as possible to guide the overall development of the engine.

- Schedule risk mitigated by adding spare hardware and using 3 test facilities for engine hot fire. 


\section{J-2X Requirements and Parameters}

Nominal Vacuum Thrust

- Nominal $=294 \mathrm{k}$

- Open-loop control

Mixture Ratio

- Nominal = 5.5

- Open-loop control

Altitude Start and Orbital Re-Start

- Start at >100,000 ft.

- Second start after 100 day on orbit

Secondary Mode Operation

- Thrust $=\sim 82 \%$

- $\mathrm{MR}=4.5$

- Vacuum Thrust 240 klbf

Natural and Induced Environments

- First-stage loads on Ares I

- In-space environments for Ares V

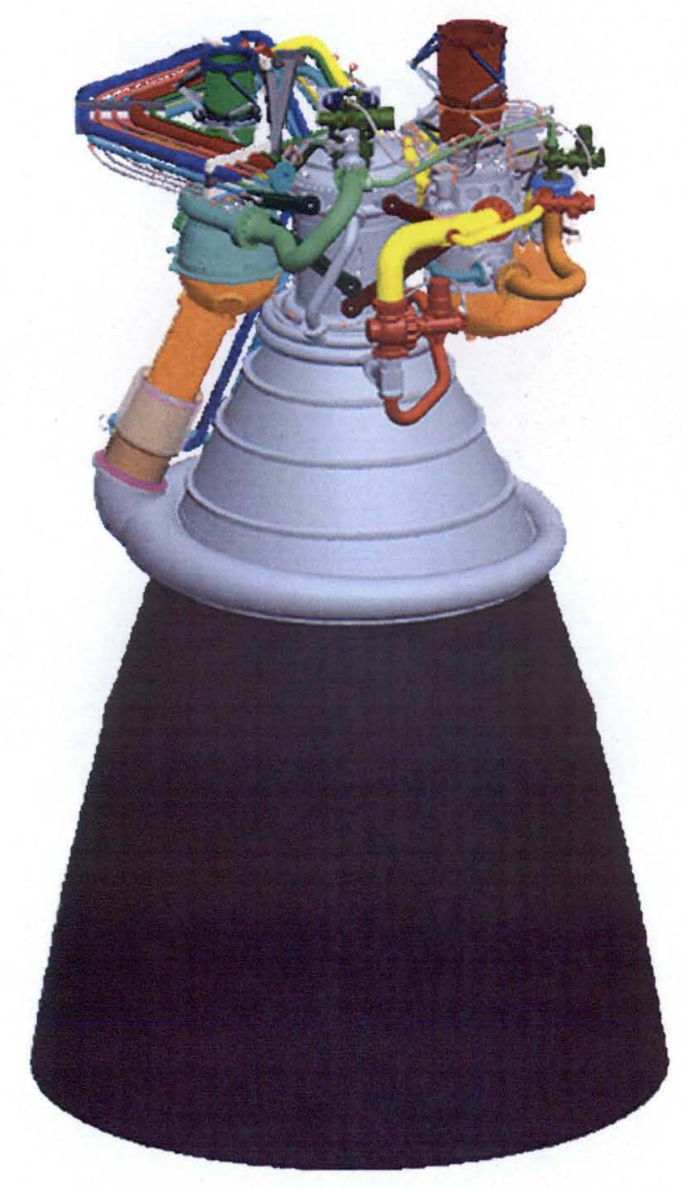

Engine Gimbal

- 4-degree square

- Drives design of flexible inlet ducts and gimbal block

Health and Status Monitoring and Reporting Data Collection for Post-Flight Analysis

Engine Failure Notification

- Drives towards controller versus sequencer

- Drives software development and V\&V

Minimum Vacuum Isp $=\mathbf{4 4 8} \mathrm{sec}$

- Drives size of nozzle extension

- Drives increased need for altitude simulation test facility

- Nozzle Area Ratio 92:1 


\section{J-2X Description}

- Propellants - Liquid Hydrogen and Liquid Oxygen

- High energy

- Gas-generator cycle

- Same cycle as that used for J-2, F-1, RS-68, and many other engines

- Simple to develop and operate

- Not as intrinsically efficient as staged-combustion or expander cycle

- Two turbopumps (Oxygen/Hydrogen)

- No boost pumps

- Powered by single, fuel-rich gas generator

- Turbines arranged in series with exhaust dumped into nozzle

- Very large diverging nozzle and high performance main injector

- To achieve performance comparable to staged-combustion engine

- Pneumatic valve actuation

- Spring-loaded so as to provide for safe shutdown in the event of loss of electrical power or pneumatic pressure

- On-board engine controller

- Start-up and shut down pre-programmed

- Open-loop control - does not actively control to mixture ratio and power level

- Controls to commanded operational points (two points)

- Engine health monitoring (shut down if over "redline") 


\section{J-2X Heritage Features}

Gimbal Block

\section{Turbomachinery}

- Based on J-2S MK-29 design

- Beefed up to meet J-2X performance

- Altered to meet current NASA design standards

\section{Gas Generator}

- Based on RS-68 design

- Scaled to meet J-2X needs

\section{Engine Controller}

- Based on directly on RS-68 design and software architecture

Tube-Wall RegenerativelyCooled Nozzle Section

- Based on long history of RS-27 success (Delta II/III)

\section{Heat Exchanger}

- Based on J-2 experience on as used on S-IVB
- Based on J-2 \& J-2S design

- Potential upgrade to more modern, demonstrated materials

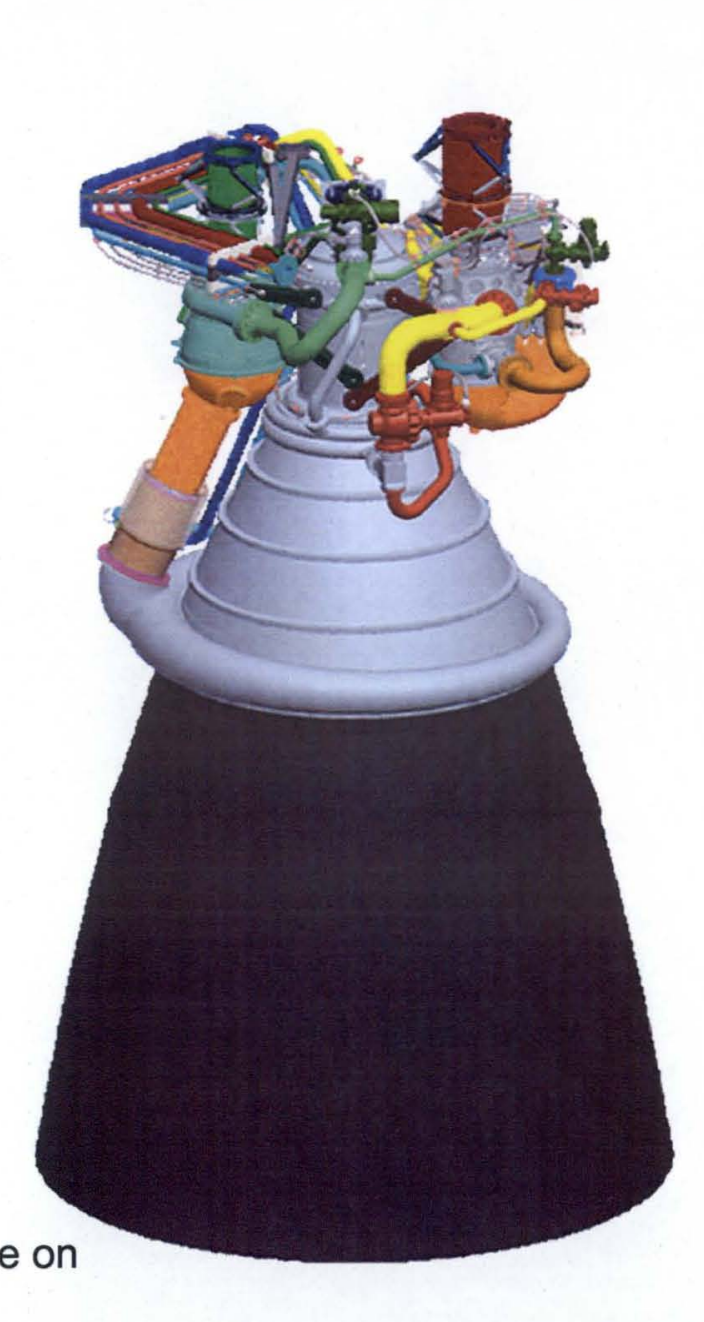

Flexible Inlet Ducts

- Based on J-2 \& J-2S ducts

- Adjusted to meet J-2X performance

- Altered to meet current NASA design standards

Open-Loop Pneumatic Control

- Similar to J-2 \& J-2S design
Valves
- Ball-sector traceable to XRS-2200 and RS-68
HIP-bonded MCC
- Based on RS-68
demonstrated technology

\section{Nozzle Extension \\ - Based on RL10-B2 experience}

\section{The $\mathrm{J}-2 \mathrm{X}$ engine is based on heritage systems with directly traceable flight experience.}




\section{J-2X Engine Layout}
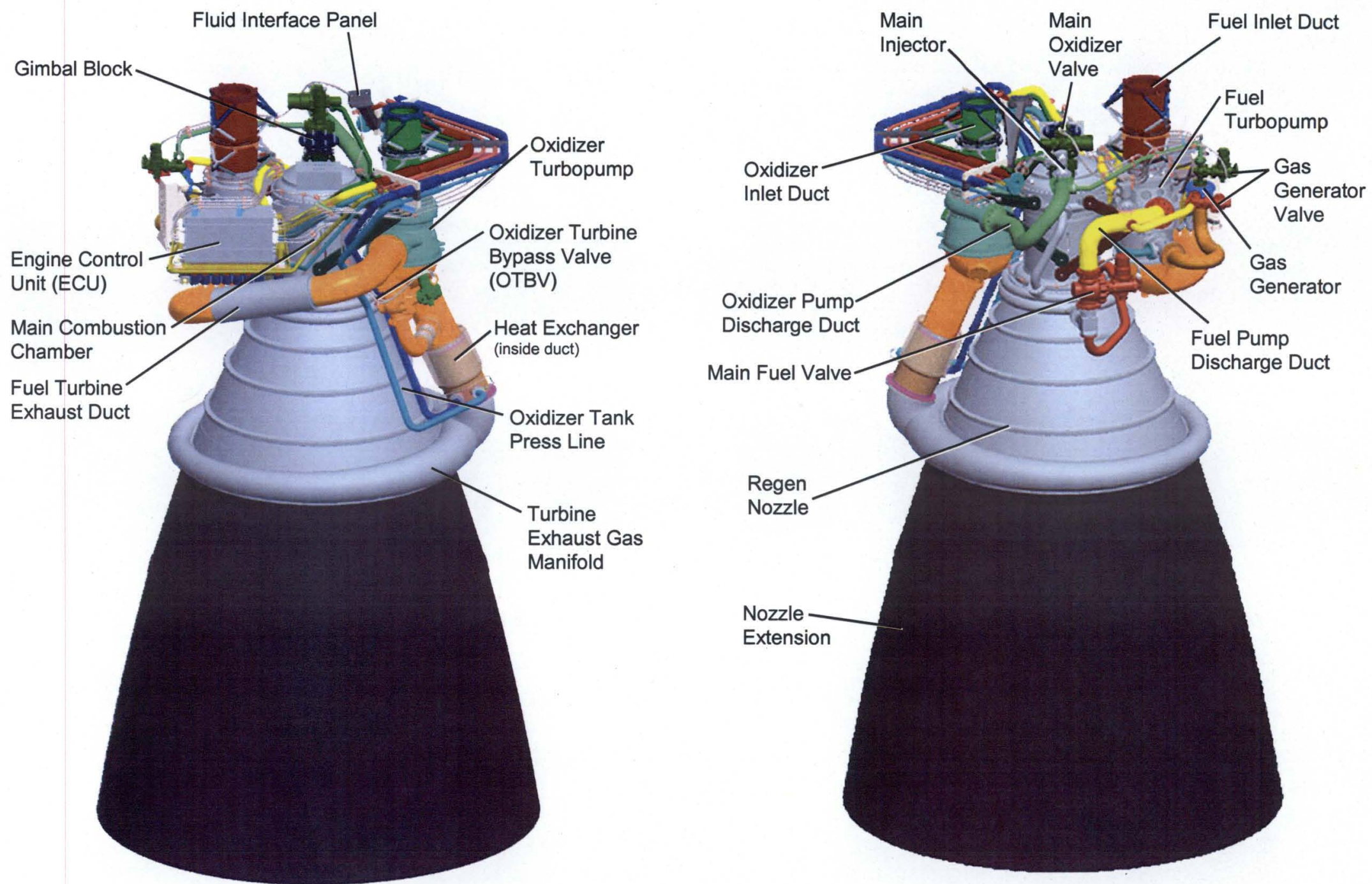


\section{J-2X System Development Plan Overview}

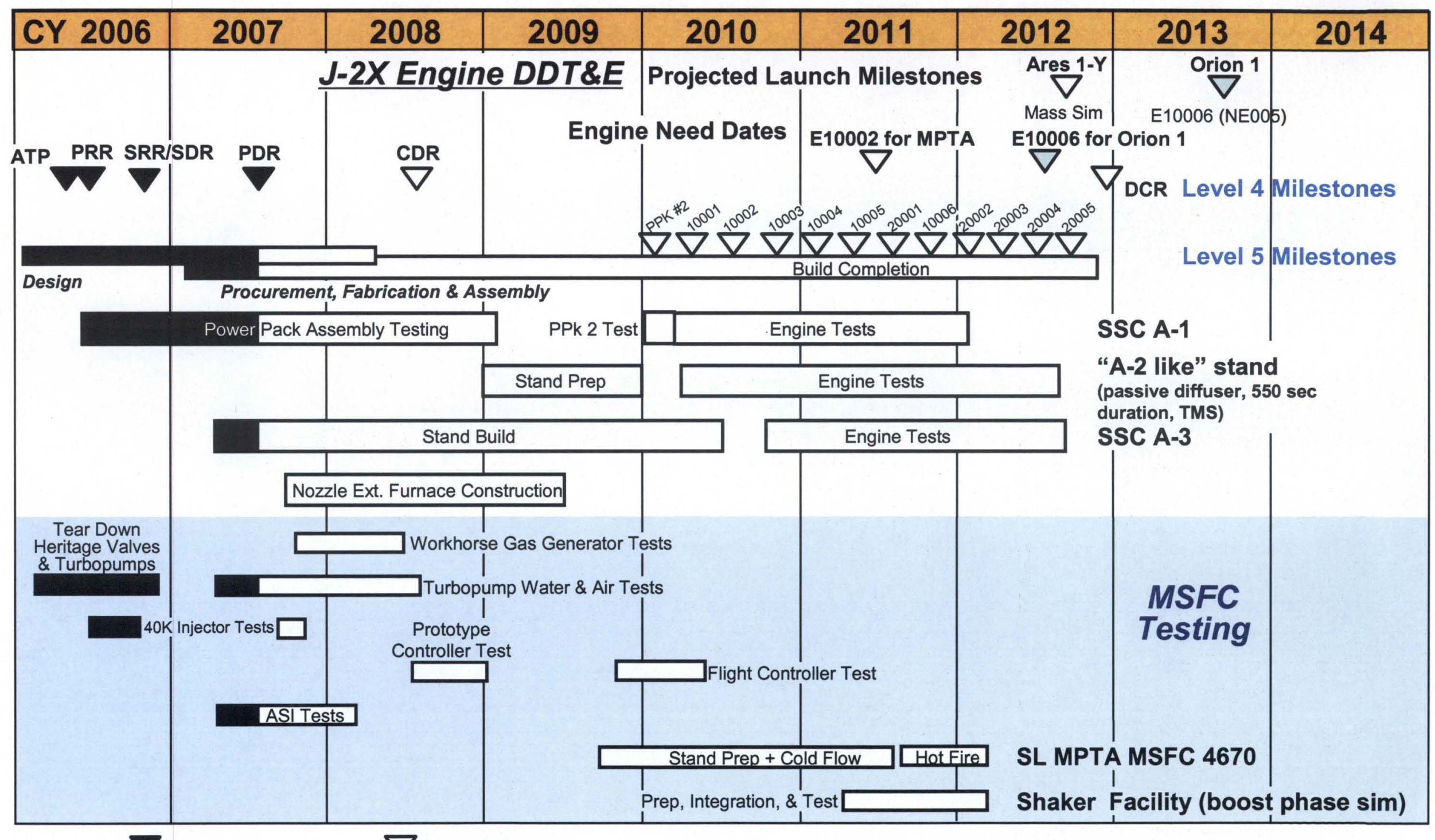

Complete

Projected Completion 


\section{Progress: Smoke and Fire}

- J-2X subscale injector testing at MSFC, 2006-2007

- $32 \mathrm{~J}-2 \mathrm{X}$-focused tests

- 28-, 40-, and 58-element inserts

- Thrust levels: less than 20,000 lbf

- Chamber pressures: 8501,500 psig

- Mixture Ratios: 4.8 to 6.9

- Fuel manifold temperatures: 100 to 300 degrees Rankin

- Other components to be tested: gas generator, turbopumps, and igniters

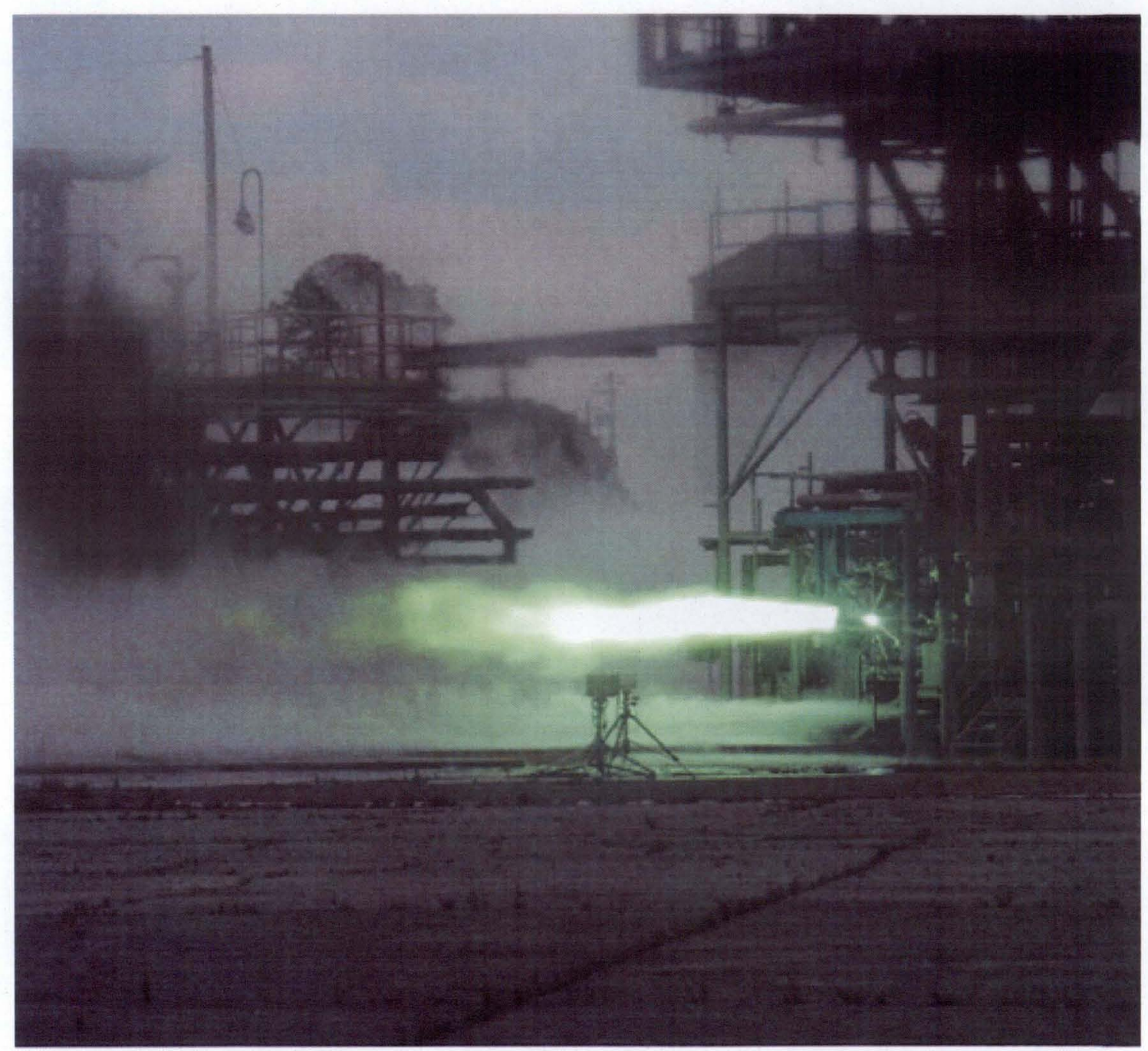



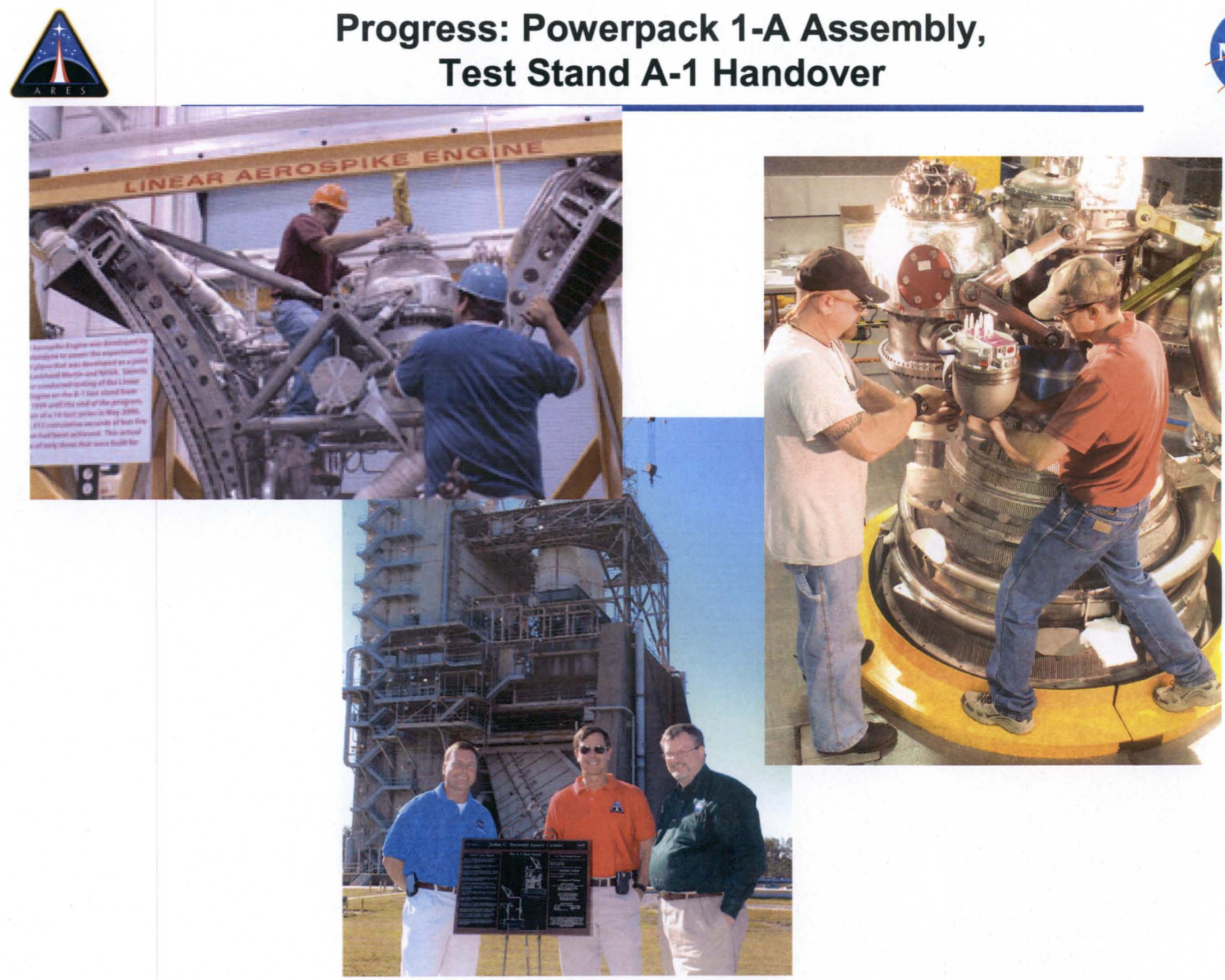


\section{Progress: Resync Review Selects Composite Nozzle}
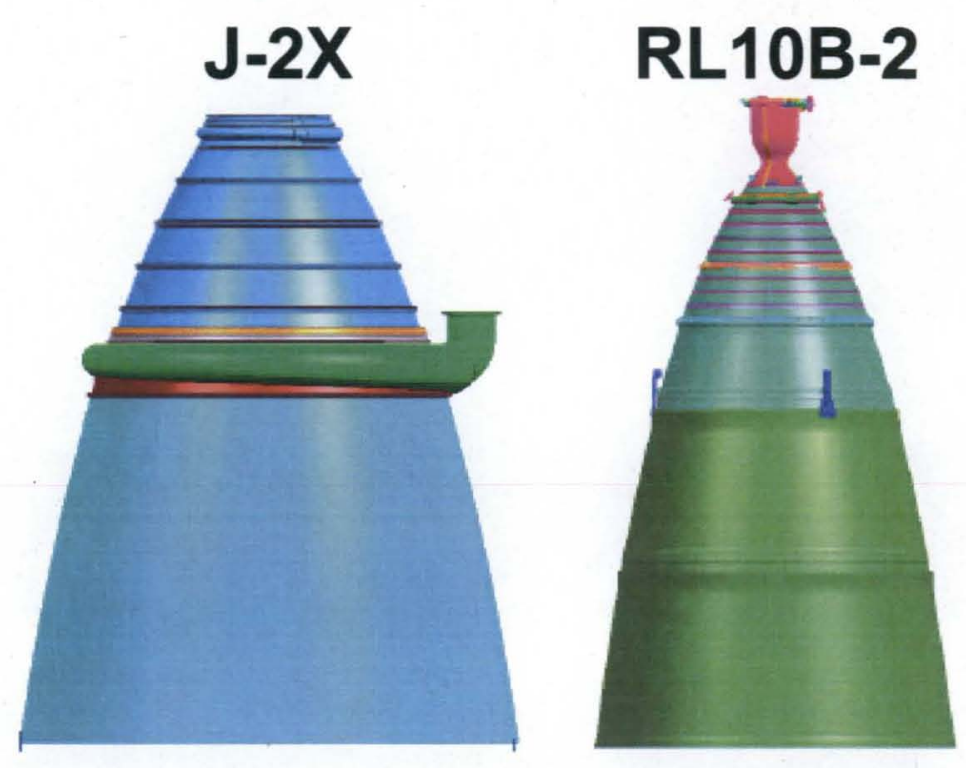

- 3D Naxeco Carbon-Carbon composite skirt from SPS with modular PWR TEG design

- Best balance of technical margin, application readiness and affordability

- Significant weight advantage and thermal risk mitigation vs. metallic designs

- Based on the RL10B-2 flight proven configuration

- Two cone configuration to improve manufacturing throughput and reduce manufacturing risk.

- The J-2X nozzle extension will be the largest shell nozzle extension for a liquid rocket engine created to date 


\section{Progress: Altitude Test Facility Decision}

Stennis Space Center A-Complex

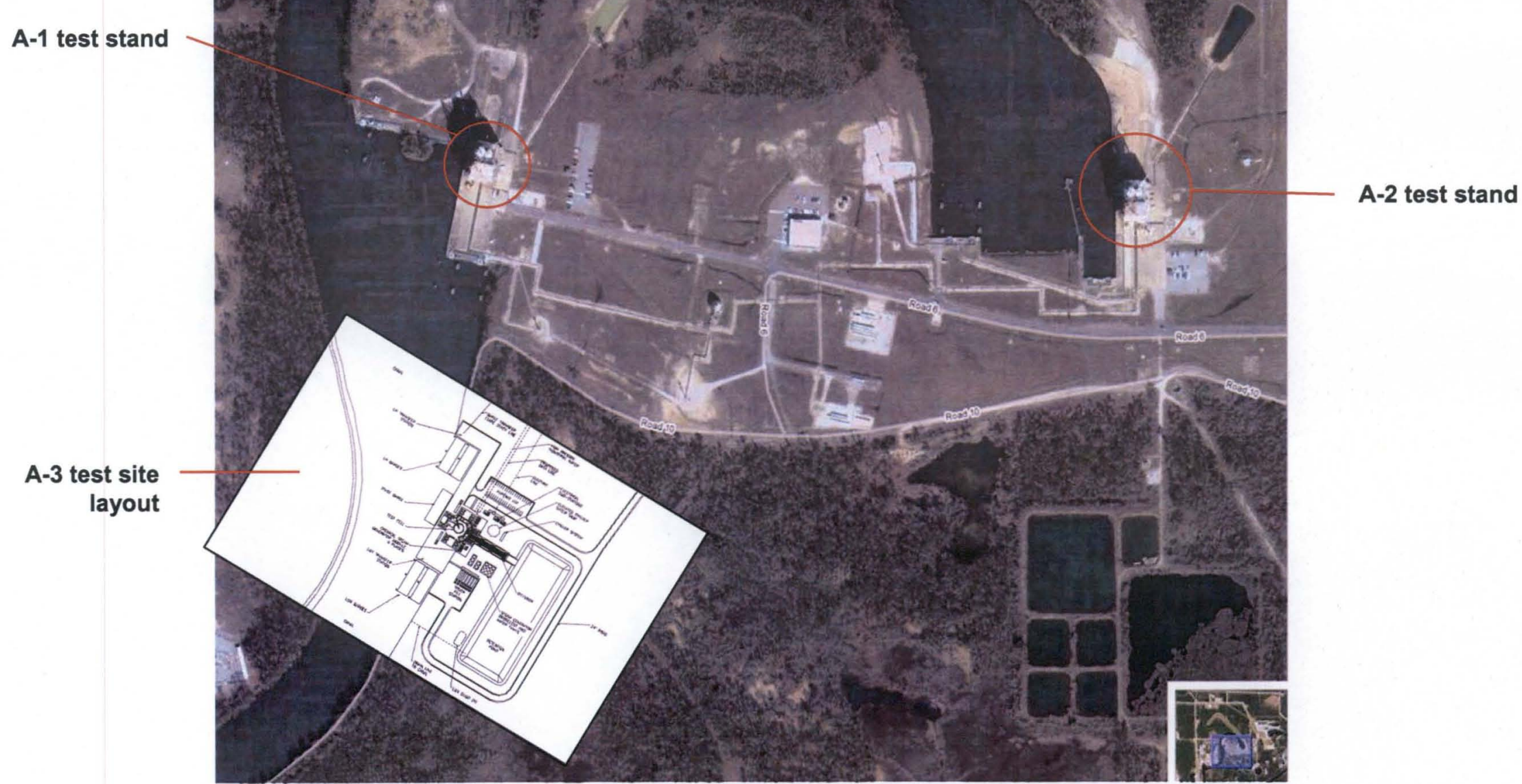




\section{Progress: Test Facilities - Continued}

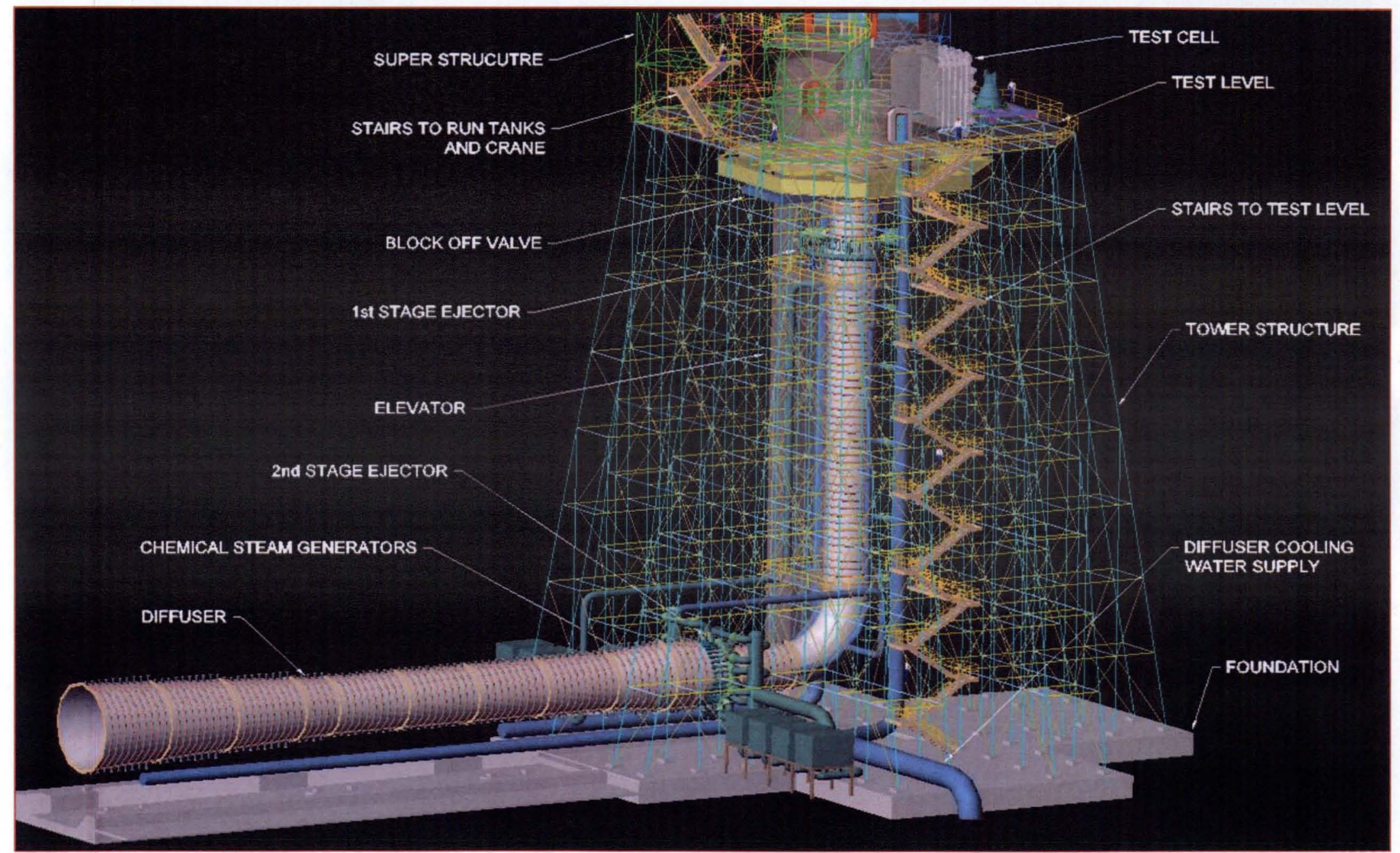




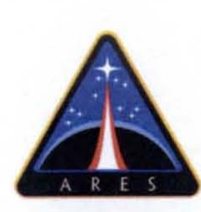

\section{Test Stand A-3 Site Preparation July '07} Groundbreaking August ' 07

Facility Activation Summer 2010
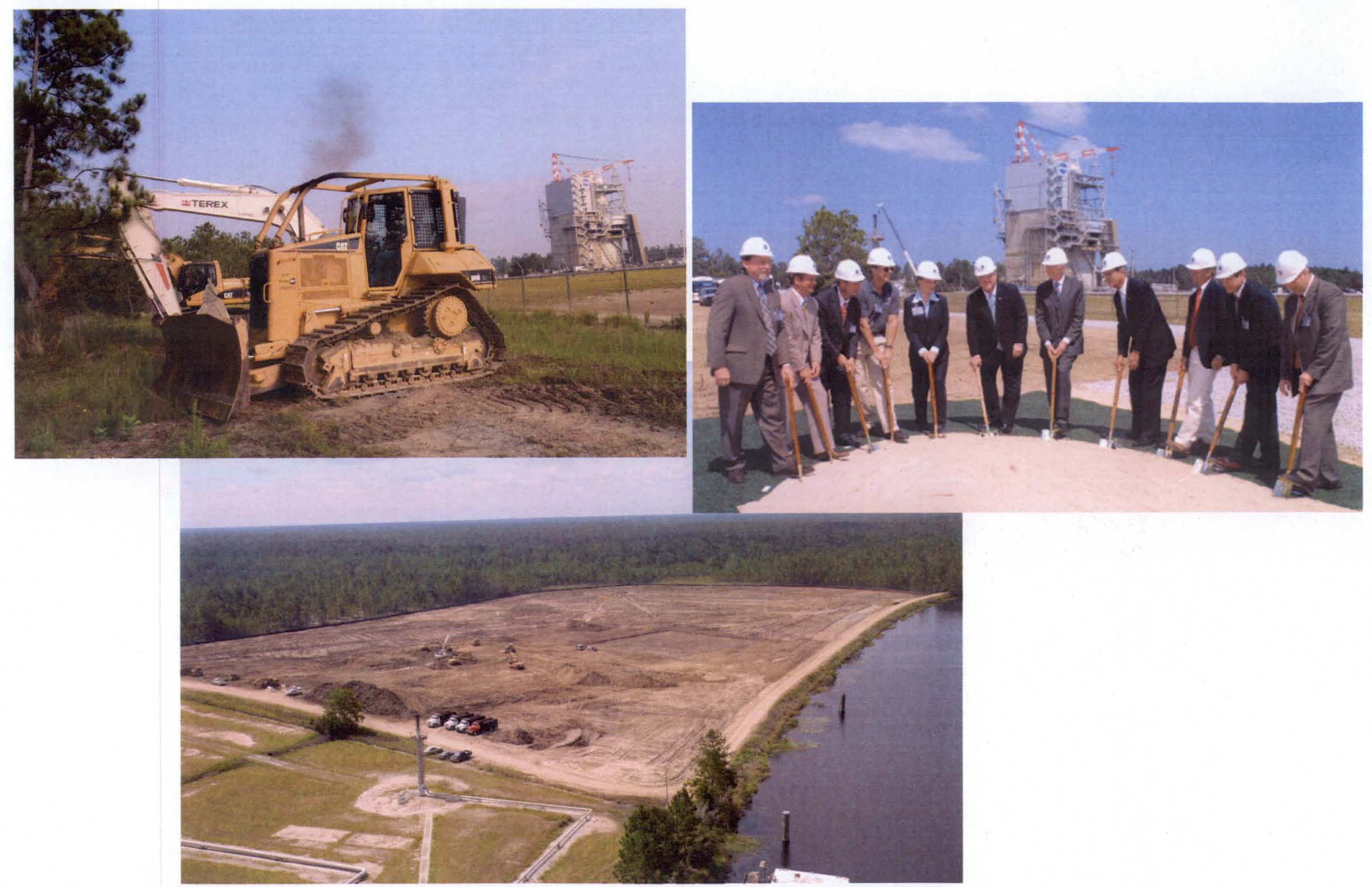


\section{Test Stand A-2 Handover}

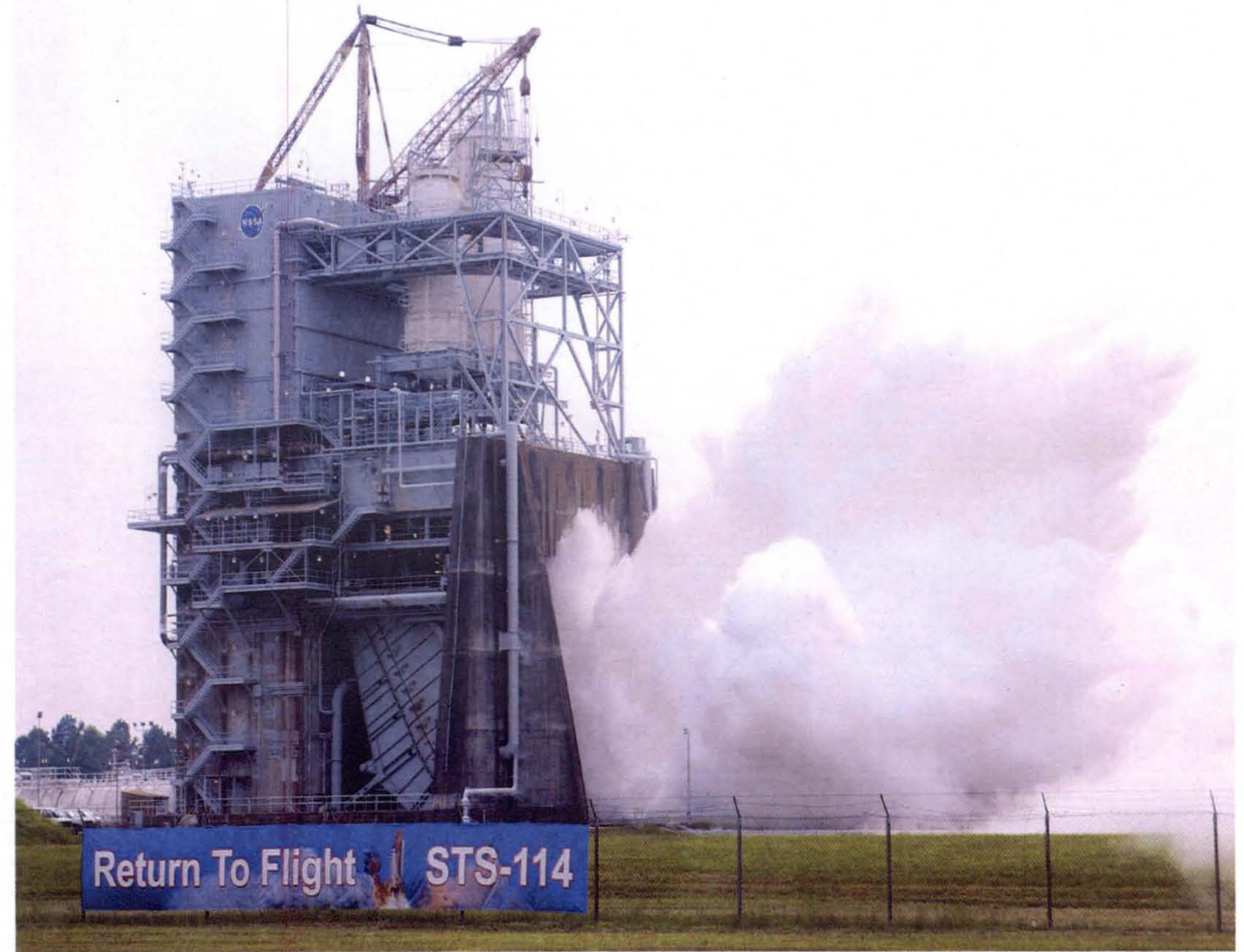

- J-2X schedule reflects July 2009 handover, early 2010 testing

- SSME and J-2X will meet in March 2009 for final decision 


\section{Recent Developments}

- DDT\&E Contract: Pratt \& Whitney Rocketdyne, ATP July 16, 2007, \$1.2 billion, ground and test flight engines, extends through Design Certification Review in December 2012

- Additional development hardware: 1 assembled engine, 1 unassembled spare, 4 sets of long lead hardware through first 18 months of 36-month manufacturing cycle.

- Successful PDR August 2007: system safety, software development work needed before July 2008 Critical Design Review

-52-element subscale main injector, workhorse gas generator, turbomachinery water flow and air flow tests at MSFC under way or pending

- Powerpack 1-A installation pending for first test phase in November

- Nozzle extension delta PDR fall 2007, Naxeco to Novoltex material change pending due to material availability, subcontract pending with Snecma

- Draft Interface Control Document with Upper Stage, maturing toward Upper Stage PDR May 2008

- Aggressively maturing design for long lead hardware for Powerpack 2 and first engine tests 


\section{J-2X Summary}

- The J-2X will be the workhorse upper stage engine for the next generation of space exploration

- The overarching intent is to keep the engine as simple as possible while still fulfilling the challenging performance requirements imposed

- Based almost entirely on Technology Readiness Level = 9 technology

- Development schedule is short and already quite active with PDR completed August 2007 and CDR scheduled for August 2008

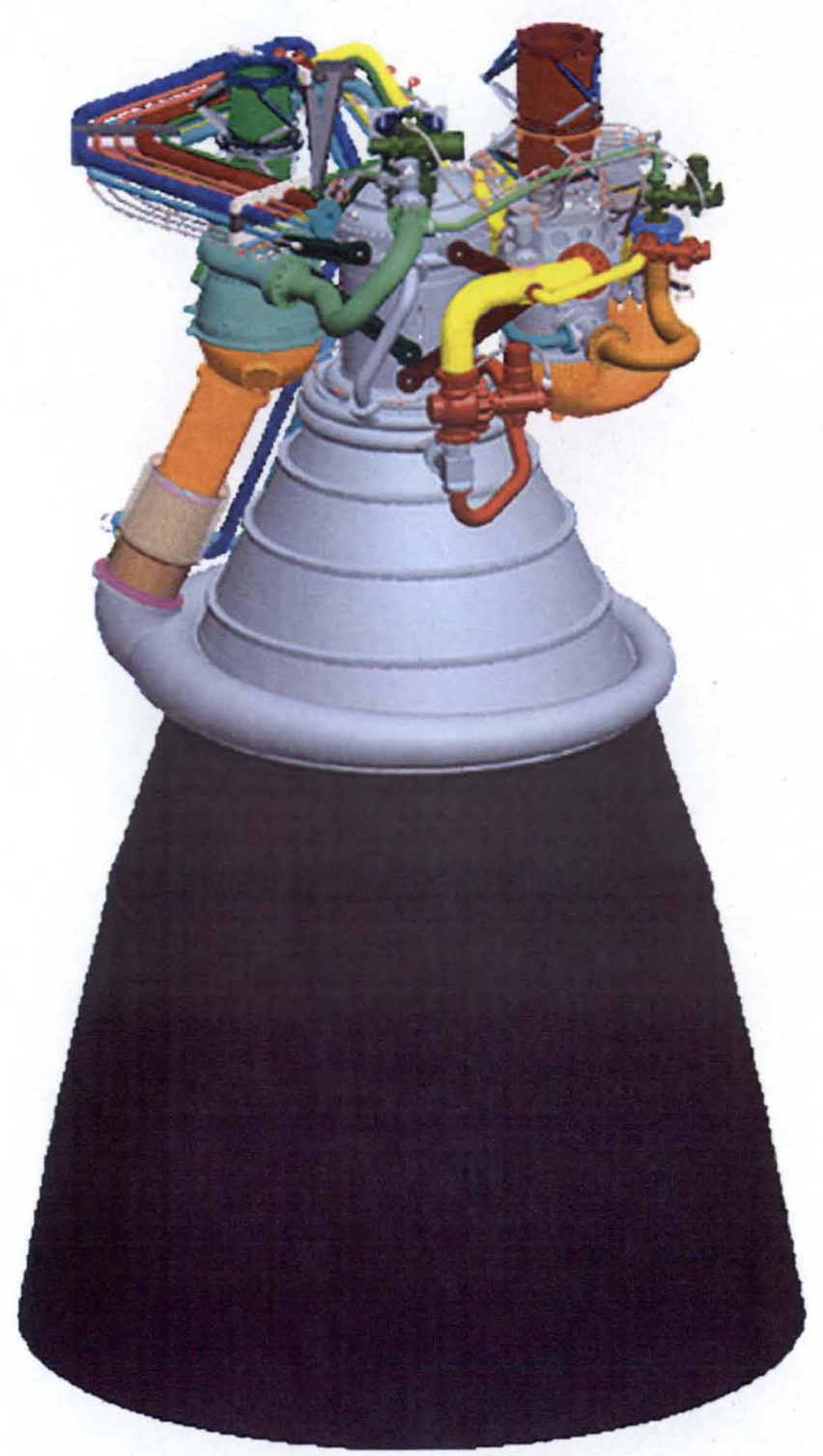




\section{More Information/Conclusion}

- Thomas D. Byrd

Thomas.D.Byrd@NASA.Gov

(256) 544-7147

- Ares public website: www.nasa.gov/ares

-Questions? 